\title{
Emergency thoracic ultrasound and clinical risk management
}

\author{
This article was published in the following Dove Press journal: \\ Therapeutics and Clinical Risk Management \\ 9 February 2017 \\ Number of times this article has been viewed
}

\author{
Maria Concetta Interrigi' \\ Francesca M Trovato 2,3 \\ Daniela Catalano ${ }^{3,4}$ \\ Guglielmo M Trovato 3,5 \\ 'Accident and Emergency \\ Department, Ospedale Cannizzaro, \\ Catania, ${ }^{2}$ Accident and Emergency \\ Department, Ospedale Civile, \\ Ragusa, ${ }^{3}$ Department of Clinical \\ and Experimental Medicine, \\ The School of Medicine, University \\ of Catania, ${ }^{4}$ Postgraduate School of \\ Clinical Ultrasound, Department of \\ Clinical and Experimental Medicine, \\ Azienda Ospedaliero-Universitaria \\ Policlinico, University of Catania, \\ ${ }^{5}$ Postgraduate School of e-Learning \\ and ICT in Health Sciences, The \\ School of Medicine, University of \\ Catania, Catania, Italy
}

Purpose: Thoracic ultrasound (TUS) has been proposed as an easy-option replacement for chest X-ray (CXR) in emergency diagnosis of pneumonia, pleural effusion, and pneumothorax. We investigated CXR unforeseen diagnosis, subsequently investigated by TUS, considering its usefulness in clinical risk assessment and management and also assessing the sustainability of telementoring.

Patients and methods: This observational report includes a period of 6 months with proactive concurrent adjunctive TUS diagnosis telementoring, which was done using freely available smartphone applications for transfer of images and movies.

Results: Three hundred and seventy emergency TUS scans (excluding trauma patients) were performed and telementored. In 310 cases, no significant chest pathology was detected either by CXR, TUS, or the subsequent work-up; in 24 patients, there was full concordance between TUS and CXR (ten isolated pleural effusion; eleven pleural effusion with lung consolidations; and three lung consolidation without pleural effusion); in ten patients with lung consolidations, abnormalities identified by CXR were not detected by TUS. In 26 patients, only TUS diagnosis criteria of disease were present: in 19 patients, CXR was not diagnostic, ie, substantially negative, but TUS detected these conditions correctly, and these were later confirmed by computed tomography (CT). In seven patients, even if chest disease was identified by CXR, such diagnoses were significantly modified by ultrasound, and CT confirmed that TUS was more appropriate. The overall respective individual performances of CXR and TUS for the diagnosis of a pleuralpulmonary disease in emergency are good, with accuracy $>95 \%$.

Conclusion: About $20 \%$ of pneumonia cases were detectable only by CXR and $20 \%$ only by TUS and not by CXR; ie, about $40 \%$ of patients may have been misdiagnosed if, by chance, only one of the two tools had been used. The concurrent use of TUS and CXR increases the overall sensitivity and specificity. The contribution of expert telementoring and final reappraisal is a valuable and sustainable element for emergency physicians' training and performance, contributing reasonably to mitigation of clinical risks.

Keywords: echography, pneumonia, pneumothorax, pleural effusion, diagnostic performance

\section{Introduction}

Clinical risk assessment and management is a process relevant in emergency diagnosis and standardized therapeutics. ${ }^{1}$ Health care itself is inherently risky and although it would be impossible to eradicate all harm, there are many activities and actions that can be introduced in order to minimize the occurrence of errors or mitigate its consequences. The key points are: establish the context, and then identify, analyze, evaluate, and treat the risks and their reciprocal relationships (Figure 1).

A further step is the feedback phase, ie, communicate and respond, monitor and review (Figure 2).

\footnotetext{
Correspondence: Guglielmo M Trovato Via Santa Sofia 78, Padiglione 4, Policlinico dell'Università di Catania, Catania 95100, Italy

Tel +39095378 I533

Fax +39095378 I549

Email guglielmotrovato@unict.it
} (c)
hereby accept the Terms. Non-commercial uses of the work are permitted without any further permission from Dove Medical Press Limited, provided the work is properly attributed. For permission for commercial use of this work, please see paragraphs 4.2 and 5 of our Terms (https://www.dovepress.com/terms.php). 


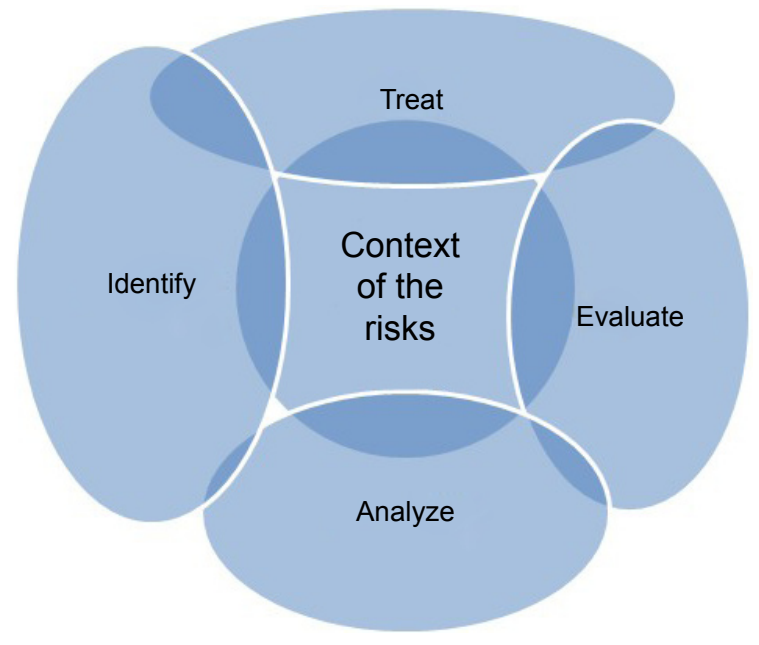

Figure I Concept map of the context of the risks.

A useful construct is to divide risk analysis into two components: 1) risk assessment (identifying, evaluating, and measuring the probability and severity of risks), and 2) risk management (deciding what to do about risks). Clinical risk management allows identification of potential errors. ${ }^{2}$ Ultrasound examination performed in emergency/urgent conditions has long been recognized and confirmed by thousands of studies, ${ }^{3}$ but some of them detected controversial elements on criteria, ${ }^{4-6}$ reliability, ${ }^{7,8}$ and even application. ${ }^{9-12}$

The mostly relevant and questionable topics related with clinical risk management ${ }^{13}$ are:

1. The claim that short periods of formal study and training are sufficient to perform consistent and effective procedures: this statement is not widely agreed upon and not reasonable. ${ }^{8}$

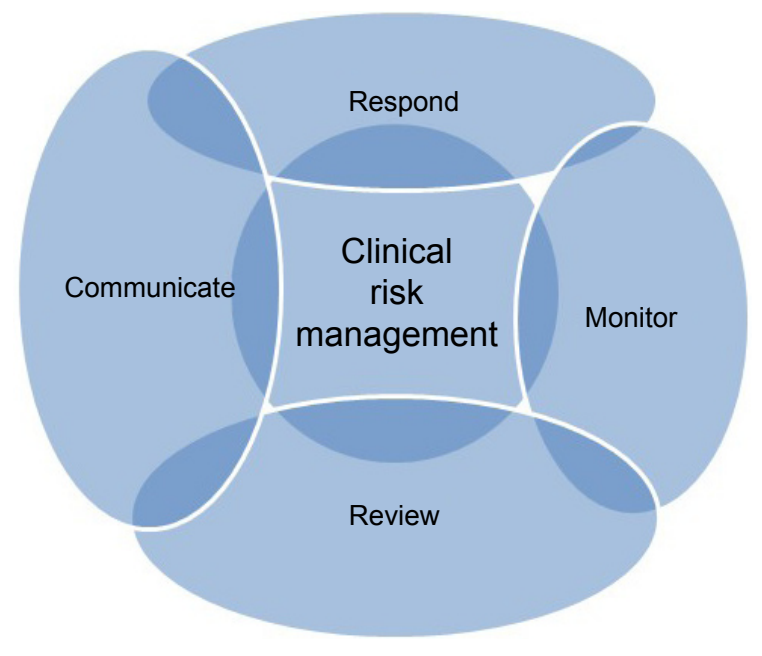

Figure 2 Concept map of clinical risk management.
2. The concept that the process can work as a standalone definite procedure. ${ }^{9}$

Actually, emergency medicine residency in the United States increasingly includes a 1 year full-time fellowship in emergency ultrasound. ${ }^{14-25}$ In Italy, there are few identical models, and among them the Postgraduate School of Clinical Ultrasound of the School of Medicine of the University of Catania offers a training curriculum that addresses all the aspects of diagnostic ultrasound. ${ }^{8,26-29}$ In emergency medicine, ECOFAST, ${ }^{30}$ or e-FAST, ${ }^{31}$ ie, focused assessment with sonography for trauma (commonly abbreviated as FAST) is a rapid bedside ultrasound examination. It is performed by surgeons, emergency physicians, and paramedics, mainly focused as a screening test for identifying fluid or blood around the heart (pericardial effusion) or abdominal organs (hemoperitoneum) or in the chest (pleural effusion but also pneumothorax) after trauma. Actually, training in "bedside ultrasound" (ultrasound at the bedside) ${ }^{32,33}$ or better, "point of care ultrasound" (POCUS) $)^{34,35}$ (ultrasound on site intervention), "echoscopy", ${ }^{36}$ or, in case of emergencies, emergency ultrasound is provided, regretfully as short courses, with limited articulation and often delivered to many participants. ${ }^{37}$

Thoracic ultrasound (TUS) clinical criteria were well defined by the original studies performed in USA and Europe, and thereafter used worldwide. As a consequence, reliable ultrasound imaging criteria for pleural effusions, ${ }^{9,38}$ for pulmonary consolidations due to cancer or pneumonia, ${ }^{4,12,39}$ for pneumothorax ${ }^{40-43}$ and, with controversial reliability, for pulmonary embolism ${ }^{44,45}$ have been well established and successfully applied. Also conditions that may be associated with trauma, such as pulmonary contusion, ${ }^{46}$ hemothorax or hemopneumothorax, ${ }^{47}$ either by penetrating rib fractures or blunt trauma, are capable of being diagnosed in a timely manner by experienced emergency US clinicians, or at least highly suspected, by TUS. Other less frequent conditions, but with potential presentation in urgency, are congenital lung cysts ${ }^{29}$ malformations, ${ }^{48}$ abscesses,${ }^{49}$ or different air-liquid conditions in cavities. ${ }^{9}$

All these lesions, at least in part, must "touch" the chest wall, ie, should be subpleural for being visible by ultrasound: alveolar air prevents the passage of ultrasound and its imaging effect. ${ }^{9}$ Moreover, it is required that the acoustic window is at least partly aligned with the lesion, considering that about $30 \%$ of the pleural-pulmonary surface is in various ways "obscured" from the ultrasound point of view by bones (shoulder blade, clavicle, ribs). ${ }^{9}$ Notwithstanding these limitations, clear-cut definitions of criteria and patterns of images well identifiable in the chest are available and are easily 
achievable, especially by using convex probes and linear probes at higher frequency $(7-10 \mathrm{MHz})$. It must be outlined that lung consolidation, caused by pneumonia or cancer, is not discriminated by ultrasound or by using more advanced ultrasound techniques such as transient Elastography ${ }^{50}$ or contrast-enhanced ultrasound. ${ }^{51}$

The limitations of these imaging approaches ${ }^{52}$ can be summarized as:

1. Inherent limitations of the procedure;

2. Insufficient preparation of the operators for this ultrasonographic method;

3. Lack of availability or quality of provided ultrasound equipment;

4. Restricted period of operation that can limit the accurate use of ultrasound tool for selected patients. This last is certainly the most relevant factor, and not only in emergency.

Context analysis (Figure 1) is a preliminary point for a sustainable management, and effective mitigation of risks can be better pursued with appropriate mentorship and reappraisal (Figure 2). The specificity of problems in emergency ultrasound is briefly itemized in Figure 3.

Current information and communication technologies allow easy and instant transmission of images and video to get a second diagnostic opinion by colleagues who practice the same technologies. ${ }^{53-55}$ The sustainability of telementoring by smartphone application is increasingly demonstrated in radiology, dermatology, surgery, and emergency medicine. $^{56-58}$

Regretfully, most of the recently published studies comparing TUS with roentgenologic imaging are designed as a kind of competition between heterogeneous environments

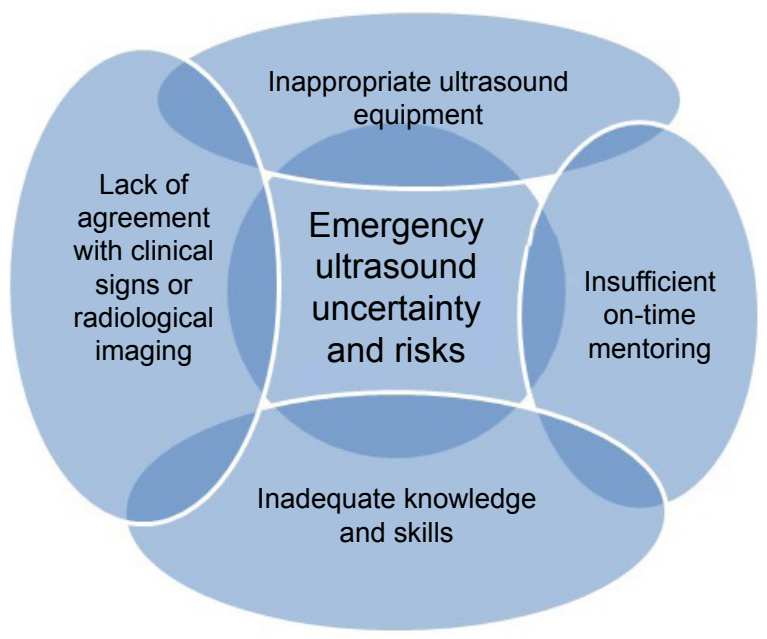

Figure 3 Concept map of emergency ultrasound uncertainty and risks. of urgency/emergency physicians and a "counterpart" of radiological expertise..$^{59,60}$ Moreover, it is often described in the methods of several published reports that the skills have been acquired by the physicians and disseminated within the emergency departments with short-term training courses and practical training implementation with a limited number of case studies (even only 30 personal cases or less). ${ }^{27,59-62}$ While this may be "the real world", this is definitely not a desirable or justifiable world. ${ }^{61}$

The benefits of second opinions in radiology and pathology are recognized. For instance, teleultrasonography with telementoring ${ }^{56-58}$ between Emergency Medicine residents and experienced mentors was effectively applied in diagnosing pediatric acute appendicitis in an emergency clinical setting. ${ }^{63}$ The usefulness of TUS for the diagnosis of acute heart failure is limited, since other clinical and technical tools are more suitable. ${ }^{64-78}$ Pediatric ultrasound, ${ }^{79,80}$ rheumatology ${ }^{81}$ and interventional diagnostic procedures ${ }^{82}$ are also less frequently relevant in a general emergency facility.

The purpose of this report is to investigate the occurrence, if any, of "unforeseen diagnosis", provided by TUS in addition to the usual criteria and to display an articulated and sustainable learning model by expert telementoring. This novel approach is addressed for the management of clinical risk in TUS emergency; accuracy of the process is defined by the comparison of chest X-ray (CXR), TUS, and final diagnosis. Patients referred to emergency facilities for trauma of any severity are not included in this study; this exclusion criterion should allow for the assessment of a more homogeneous group of subjects. Moreover, trauma patients are a small percentage of the population referred to emergency and accident departments, and pleura-pulmonary problems may be not suitable for detection by TUS. Actually, in trauma patients the access to appropriate acoustic windows is, in several instances, difficult (anatomic barriers, bandages, and limitation of patients' mobility) if not impossible.

\section{Patients and methods}

The present study describes a 6 month period of specialist activity of an emergency department physician, to display, in the subsets of difficult or unexpected thoracic diagnosis, the performance of TUS imaging; the context includes the prompt availability of all radiological facilities. The interaction of TUS telementoring, provided by another colleague, in another city and hospital, with a greater specific expertise in TUS, was devised to assure a concurrent mentorship by the school. This training has included a subsequent reassessment of clinical cases by the Ultrasound Course Lecturer in TUS 
and by the Director of the School of Clinical Ultrasound, with a reappraisal overview of all the available information (Figure 4). The study and the manuscript were approved by the Institutional Review Board of the Project Office of the AOU Policlinico, the University Hospital of Catania, and the Review Board of the Postgraduate School in Clinical Echography of the University of Catania, Italy; written informed consent of the patients and of the research participants as authors was provided according to the national ethical and privacy regulation.

A pictorial essay displays the main features of the conditions detected by TUS in emergency medicine (Video S1).

The approach was clinical and instrumental and included the following:

1. clinical history;

2. clinical examination of chest, neck, joints, and abdomen;

3. sequential ultrasound examination of the abdomen, thorax, pericardium;

4. focus on pain symptoms: chest, abdomen (with or without distention), lumbar region, neck;

5. focus on dyspnea and/or cough and/or fever with detection of humid or dry lung sounds, chest dullness, heart and/or pleura-pericardial sounds, and/or jugular congestion, checking also the mobility of the diaphragm and evaluating the collapsibility of the cava vein.

Patients included in this study, apart from the abovementioned criteria, should have satisfied one of these two criteria of unexpected diagnosis after TUS examination:

1. Patients in whom chest radiography was not diagnostic or totally negative and in whom TUS suggested evidence of a specific pathology (consolidation, effusion, pneumothorax), later confirmed by computed tomography (CT).

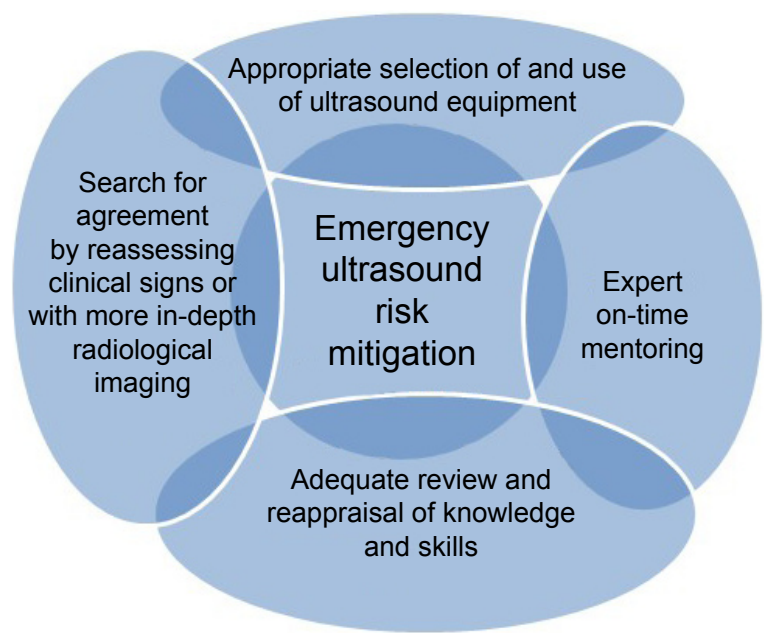

Figure 4 Concept map of emergency ultrasound risk mitigation.
2. Patients in whom chest disease was detected on chest radiographs, and in whom a specific condition was further detailed, or differently addressed by the ultrasound procedure, and confirmed by CT.

Exclusion criteria: trauma, patients with noninvasive pulse oximetry $\left(\mathrm{SpO}_{2}\right)$ lower than $92.0 \%$, those with clinical or instrumental signs of heart failure, those undergoing hemodialysis or having severe renal insufficiency, and those with a known diagnosis of solid or blood tumors.

TUS was done according to a defined work-up, ${ }^{9,39,81,83}$ in patients with the abovementioned symptoms and/or physical signs of pneumonia or other chest disease, during the physical examination and before definitive radiographical evidence, if any, was available. Sonography was performed via Esaote Technos MPX - My Lab 6 (Esaote, Genoa, Italy) and/or the Sonosite M-Turbo portable ultrasound system (Sonosite Inc., Bothell, WA, USA), on pulmonary assessment settings, using a $3.5-8-\mathrm{MHz}$ convex probe in adults and an 8-12.5-MHz linear probe in adolescents and children. TUS assessed ${ }^{9,39,81,83}$ the chest of each of the patients posteriorly, laterally, and anteriorly and was integrated with an abdomen US examination. TUS was generally conducted with the patient in a sitting position, although the few patients (predominantly children) likely to experience severe discomfort during the procedure were scanned in a semisupine position. A systematic examination of all intercostal spaces was performed and TUS images, if present, were assessed for the number, location, shape, size, and breath-dependent changes of consolidation areas. Two main patterns of lung consolidation attributable to pneumonia were defined: hypoechoic consolidation and mixed consolidation. The presence of air bronchogram, fluid bronchogram, and basal pleural effusion was also reported. The size of the consolidation area was measured longitudinally and transversally, using the longest measurement, ie, the maximal length of the consolidation area visible by TUS, for data analysis. For the purpose of this report, data on the measurements are not detailed.

The second opinion was provided outside the hospital facility by a mentor (FMT), an expert in clinical ultrasound, who answered questions related to the images and US movies of the actual patient. Images and movies were transferred by WhatsApp $^{\circledR}$ (WhatsApp Inc., Mountain View, CA, USA), a proprietary, cross-platform that provides encrypted instant messaging for smartphones; the transfer of sensitive data was done in accordance with standards of data protection encrypted by the end-to-end technology and was carried out anonymized and blinded. Reappraisal was performed subsequently using all the available imaging data - photos 
and videoclips - the clinical records, and the outcome information, as obtained by a short-term follow-up.

Statistical analysis (performed using SPSS 18 [SPSS Inc., Chicago, IL, USA]) was addressed to the definition of accuracy, ie, the proportion of true results (both true positives and true negatives) among the total number of cases examined. Specificity and sensitivity of the procedure are also reported to allow a plain presentation of conclusions. Each measure is calculated respectively for TUS and CXR using also the off-line Toolkit for measuring the validity and utility of general practice electronic patient records (http://www.hutchon.net/EPRval.htm). Categorical data were compared between groups using contingency tables and $\chi^{2}$ tests.

This trial is registered at www.ClinicalTrials.gov under \# NCT02985528.

\section{Results}

The study was accomplished over 6 months (FebruaryJuly 2016), with the observation of 370 patients (excluding trauma patients) by a single physician. In 310 cases, no significant chest pathology was detected either by CXR or TUS; in 24 patients, there was a full concordance between TUS and CXR (ten isolated pleural effusion; eleven pleural effusion with lung consolidations; and three lung consolidation without pleural effusion); in ten patients with lung consolidations, abnormalities identified by CXR were not detected by TUS.

In 26 patients (13 men and 13 women, age range

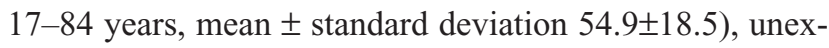
pected TUS diagnosis criteria were present:

1. In 19 patients, CXR was not diagnostic, ie, substantially negative, but TUS detected unexpected ultrasound imaging, which was later confirmed by CT. The diagnoses were as follows:

a. lung consolidation with slight pleural and/or pericardial effusion in seven patients;

b. isolated lung consolidation - defined as pneumonia by CT - in 11 patients;

c. isolated pleural effusion in one patient.

2. In seven patients, a diagnosis of a chest disease on CXR was done; however, such diagnosis was better detailed by ultrasound, and CT confirmed TUS diagnosis (one case of pneumothorax, one case of lymphangitis carcinomatosa, three cases of pneumonia, one case of isolated pericardial effusion, one case of isolated pleural effusion).

According to these results, the overall performance of CXR for the diagnosis of a pleural-pulmonary disease in emergency is good, with a sensitivity of $68 \%$ and a specificity of $99.0 \%$. Slightly greater is the sensitivity for TUS, $82.8 \%$, with an identical specificity, 99.8\%.

The overall respective individual performances of CXR and TUS for the diagnosis of a pleural-pulmonary disease in emergency, assessed as accuracy, are good, both $>95 \%$.

\section{Discussion}

Patients with chest or abdominal pain or with respiratory symptoms are frequently referred to emergency, and these occurrences are in many cases, particularly challenging. Advantages of a reliable and affordable diagnostic imaging procedure are evident and well recognized. In addition, the decisive contribution of the ultrasound, performed in conjunction with a thorough clinical examination, has been confirmed by many studies and by the daily experience of many emergency department physicians.

Whether some or all patients should undergo ultrasound examination depends on several factors. Actually, the ultrasound examination is usually performed to confirm a clinical diagnosis based on the overall assessment of the patients before doing more advanced imaging procedures.

Nonetheless, this behavior may lead to errors, and so, in our experience, a quick, early, and expert complete US chest and abdomen examination is helpful in any patient with pain, dyspnea, cough, and/or fever (Box 1).

This brief clinical contribution shows the personal experience over 6 months of activity in the emergency room, with the use of diagnostic ultrasound imaging of the chest in patients with chest pain not immediately attributable to heart disease. In the current literature, there are studies reporting experiences related to the ultrasound diagnosis of pneumothorax, and in patients with "pleuritic" chest pain, features of pain are frequently an obvious indication. As a consequence, it is not surprising that a good match of TUS with the final diagnosis is found, even with greater sensitivity than CXR. Different however, is the evaluation of the contribution of TUS in the case of pulmonary consolidations, pneumonia, neoplasms, or atelectasis by various causes, as in our contribution we are reporting; in such presentations chest pain may be present as a symptom. This is a challenging and even a "risky" subset, which may represent a paradigm also for other clinical frames:

risk management in radiology is primarily developed and fostered to help safeguard patients, working personnel and the entire organization. Protection of the organization is largely grasped in terms of finance management. Potential drawbacks are linked to unreliable results that could damage its reputation. ${ }^{14}$ 


\section{Box I TUS checklist}

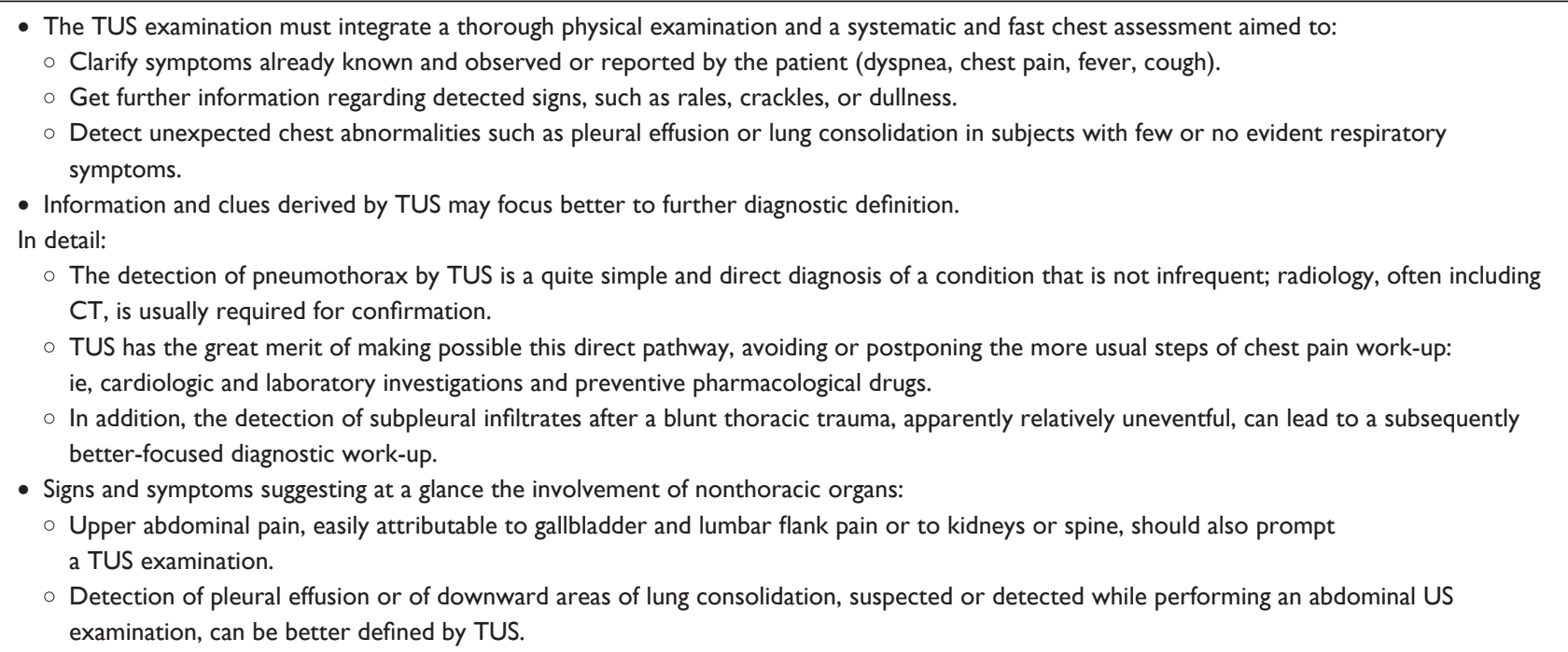

Abbreviations: CT, computed tomography; TUS, thoracic ultrasound.

Different results provided by the two examinations, TUS and CXR, are due also to the different imaging properties of thoracic organs and lesions; this is also related to the features of the two different procedures. TUS views are limited to about $70 \%$ of the pleura and lung due to the barriers of bones, mainly scapulae, and to the possibility of only exploring lesions that have pleural-subpleural contact. Reciprocally, CXR is limited in its definition of lateral and strictly subpleural images; this feature conceivably restricts the possibility of chest exploration by CXR to about $70 \%$ of the lung. When comparing CXR and TUS views, the inaccessible parts of the lung are only partly coincident.

This is a particularly sensitive topic since apart from the scientific foundation of some well-conducted clinical trials, the reference to a diffuse "good practice" for TUS diagnosis may still be a slippery slope. ${ }^{35}$

The essence of risk management is to survey all potential reasons for an inaccurate report in advance, so that procedures can be put in place to prevent them. ${ }^{14}$

There are still relevant variations in imaging test accuracy due to technical reasons of the procedure itself or due to inconclusive results and reports or due to organizational or individual professional limitations; therefore, even the analysis of associated risks has lacked uniformity in the cost-utility literature. ${ }^{13}$

The integration of TUS and CXR with more advanced radiological procedure is frequently mandatory, apart from extreme emergency conditions and in conditions where resource facilities are not available. Actually, both in emergency TUS, where unexpected clues are more frequently reported, and in elective TUS, which can also be the source of relatively unforeseeable information, the concurrent articulation of clinical and radiological assessment is needed.

There are several similarities between the analysis of the interference of hospitalization on the continuity of drug therapy ${ }^{84}$ and the strategy for clinical risk effects ${ }^{85-87}$ mitigation; a sustainable emergency procedure, such as TUS, with an affordable expert telementoring, may contribute to increase reliability and accuracy of diagnosis and timely therapeutic choices.

\section{Conclusion}

About $20 \%$ of pneumonia cases, detectable only by CXR, would have been misdiagnosed if TUS had been the sole method of diagnosis. A similar percentage of chest diseases, however, were detected only by TUS as single approach and not by CXR. However, the concurrent use of TUS and CXR, which otherwise share similar levels of individual diagnostic accuracy, greatly increases sensitivity and specificity. Novel methodologies, such as TUS contrast-enhanced ultrasound (CEUS) tools are not useful in emergency and elective differential diagnosis of lung consolidation. ${ }^{27}$ The contribution of expert telementoring and final reappraisal may be a valuable and sustainable element for empowering emergency physicians' safety and performance quality, contributing to the mitigation of clinical risks in such a subset. 


\section{Acknowledgments}

This study was conducted with the full support of the hospital diagnostic and therapeutic facilities, whose contribution is greatly appreciated.

\section{Author contributions}

This observational study is a summarized report of the daily practice of an individual doctor (MCI) in an emergency department over a period of 6 months (February-July 2016). The proactive, concurrent mentoring in the interpretation of TUS diagnosis was provided by FMT. The final reappraisal of the findings and the correlation among clinical examination, ultrasound, and CXR imaging (including radiography of the chest and CT) was done by GMT and DC. All authors contributed toward data analysis, drafting and critically revising the paper, gave final approval of the version to be published, and agree to be accountable for all aspects of the work.

\section{Disclosure}

The authors report no conflicts of interest in this work.

\section{References}

1. Thornton E, Brook OR, Mendiratta-Lala M, Hallett DT, Kruskal JB. Application of failure mode and effect analysis in a radiology department. Radiographics. 2011;31:281-293.

2. Brook OR, Kruskal JB, Eisenberg RL, Larson DB. Root cause analysis: learning from adverse safety events. Radiographics. 2015; 35:1655-1667.

3. Trovato FM, Catalano D, Trovato GM. Thoracic ultrasound: an adjunctive and valuable imaging tool in emergency, resource-limited settings and for a sustainable monitoring of patients. World J Radiol. 2016;8:775-784

4. Hendaus MA, Jomha FA, Alhammadi AH. Lung ultrasound for the diagnosis of childhood pneumonia: a safe and accurate imaging mode. Ther Clin Risk Manag. 2015;11:1817-1818.

5. Joyner CR Jr, Miller LD, Dudrick SJ, Eskin DJ, Bloom P. Reflected ultrasound in the study of diseases of the chest. Trans Am Clin Climatol Assoc. 1967;78:28-37.

6. Rosenberg HK. The complementary roles of ultrasound and plain film radiography in differentiating pediatric chest abnormalities. Radiographics. 1986;6:427-445.

7. Beckh S, Bölcskei PL, Lessnau KD. Real-time chest ultrasonography: a comprehensive review for the pulmonologist. Chest. 2002;122: 1759-1773.

8. Trovato FM, Musumeci G. Lung ultrasound: the need of an adequate training for the next generation of internists. Neth J Med. 2015;73:305.

9. Sperandeo M, Rotondo A, Guglielmi G, Catalano D, Feragalli B, Trovato GM. Transthoracic ultrasound in the assessment of and pulmonary diseases: use and limitations. Radiol Med. 2014;119:729-740.

10. American College of Emergency Physicians. Emergency ultrasound guidelines. Ann Emerg Med. 2009;53:550-570.

11. Hu QJ, Shen YC, Jia LQ, et al. Diagnostic performance of lung ultrasound in the diagnosis of pneumonia: a bivariate meta-analysis. Int $J$ Clin Exp Med. 2014;7:115-121.

12. Haller JO, Schneider M, Kassner EG, Friedman AP, Waldroup LD Sonographic evaluation of the chest in infants and children. AJR Am J Roentgenol. 1980;134:1019-1027.
13. The European Society of Radiology. Risk Management in Radiology in Europe; $I V$. Available from: http://www.myesr.org/sites/default/files/ ESR_brochure_04_2.pdf. Accessed January 22, 2017.

14. Craciun H, Mankad K, Lynch J. Risk management in radiology departments. World J Radiol. 2015;7:134-138.

15. Bellamkonda VR, Shokoohi H, Alsaawi A, et al. Ultrasound credentialing in North American emergency department systems with ultrasound fellowships: a cross-sectional survey. Emerg Med J. 2015;32: 804-808.

16. Stolz LA, Muruganandan KM, Bisanzo MC, et al. Point-of-care ultrasound education for non-physician clinicians in a resource-limited emergency department. Trop Med Int Health. 2015;20:1067-1072.

17. Keddis MT, Cullen MW, Reed DA, et al. Effectiveness of an ultrasound training module for internal medicine residents. BMC Med Educ. 2011;11:75.

18. Fodor D, Badea R, Poanta L, Dumitrascu DL, Buzoianu AD, Mircea PA. The use of ultrasonography in learning clinical examination a pilot study involving third year medical students. Med Ultrason. 2012; 14:177-181.

19. Fox JC, Schlang JR, Maldonado G, Lotfipour S, Clayman RV. Proactive medicine: the "UCI 30," an ultrasound-based clinical initiative from the University of California, Irvine. Acad Med. 2014;89:984-989.

20. Trovato GM, Catalano D, Sperandeo M. Top or flop: the need to improve knowledge and skills achieved by ultrasound medical curricula. Acad Med. 2015;90:839-840.

21. Chiem AT, Soucy Z, Dinh VA, et al. Integration of ultrasound in undergraduate medical education at the california medical schools: a discussion of common challenges and strategies from the umecali experience. J Ultrasound Med. 2016;35:221-233.

22. Dinh VA, Fu JY, Lu S, Chiem A, Fox JC, Blaivas M. Integration of ultrasound in medical education at united states medical schools: a national survey of directors' experiences. J Ultrasound Med. 2016; $35: 413-419$

23. Dinh VA, Dukes WS, Prigge J, Avila M. Ultrasound integration in undergraduate medical education: comparison of ultrasound proficiency between trained and untrained medical students. $J$ Ultrasound Med. 2015;34:1819-1824

24. Dinh VA, Frederick J, Bartos R, Shankel TM, Werner L. Effects of ultrasound implementation on physical examination learning and teaching during the first year of medical education. J Ultrasound Med. 2015;34:43-50.

25. Dinh VA, Lakoff D, Hess J, et al. Medical student core clinical ultrasound milestones: a consensus among directors in the United States. J Ultrasound Med. 2016;35:421-434.

26. Moy RJ, Chapman AL, Bapusamy A. The effectiveness of an informal teaching programme for junior doctors identifying pleural effusions using ultrasound at the bedside. J R Army Med Corps. 2010; $156: 233-235$

27. Sperandeo M, Rea G, Grimaldi MA, Trovato F, Dimitri LM, Carnevale V. Contrast-enhanced ultrasound does not discriminate between community acquired pneumonia and lung cancer. Thorax. 2016;72(2):178-180.

28. Trovato GM. Sustainable medical research by effective and comprehensive medical skills: overcoming the frontiers by predictive, preventive and personalized medicine. EPMA J. 2014;5:14.

29. Golubnitschaja O, Costigliola V, Trovato G; EPMA. EPMA summit 2014 under the auspices of the Presidency of Italy in the EU: professional statements. EPMA J. 2015;6:4.

30. Lemke HU, Golubnitschaja O. Towards personal health care with model-guided medicine: long-term PPPM-related strategies and realisation opportunities within 'Horizon 2020'. EPMA J. 2014;5:8.

31. Williams SR, Perera P, Gharahbaghian L. The FAST and E-FAST in 2013: trauma ultrasonography: overview, practical techniques, controversies, and new frontiers. Crit Care Clin. 2014;30:119-150.

32. Montoya J, Stawicki SP, Evans DC, et al. From FAST to E-FAST: an overview of the evolution of ultrasound-based traumatic injury assessment. Eur J Trauma Emerg Surg. 2016;42:119-126. 
33. Steinmetz $\mathrm{P}$, Oleskevich S, Lewis J. Acquisition and long-term retention of bedside ultrasound skills in first-year medical students. J Ultrasound Med. 2016;35:1967-1975.

34. Hew M, Tay TR. The efficacy of bedside chest ultrasound: from accuracy to outcomes. Eur Respir Rev. 2016;25:230-246.

35. Hayward M, Chan T, Healey A. Dedicated time for deliberate practice: one emergency medicine program's approach to point-of-care ultrasound (PoCUS) training. CJEM. 2015;17:558-561.

36. Laursen CB, Sloth E, Lassen AT, et al. Does point-of-care ultrasonography cause discomfort in patients admitted with respiratory symptoms? Scand J Trauma Resusc Emerg Med. 2015;23:46.

37. Barreiros AP, Cui XW, Ignee A, De Molo C, Pirri C, Dietrich CF. EchoScopy inscanning abdominal diseases: initial clinical experience. Z Gastroenterol. 2014;52:2269-2675.

38. Emergency Ultrasound Imaging Criteria Compendium. Ann Emerg Med. 2016;68:e11-e48.

39. Sperandeo M, Carnevale V, Muscarella S, et al. Clinical application of transthoracic ultrasonography in inpatients with pneumonia. Eur J Clin Invest. 2011;41:1-7.

40. Wernecke K, Galanski M, Peters PE, Hansen J. Pneumothorax: evaluation by ultrasound - preliminary results. J Thorac Imaging. 1987;2: 76-78.

41. Targhetta R, Bourgeois JM, Balmes P. Echography of pneumothorax. Rev Mal Respir. 1990;7:575-579.

42. Press GM, Miller SK, Hassan IA, et al. Prospective evaluation of prehospital trauma ultrasound during aeromedical transport. J Emerg Med. 2014;47:638-645.

43. Trovato G, Sperandeo M. A picture is worth a thousand words: the need for CT for assessment of size and distribution of pneumothorax. Intensive Care Med. 2014;40:1614-1615.

44. Joyner CR. Ultrasonic diagnosis of pulmonary embolism - the second time around. Int J Cardiol. 1984;6:116-120.

45. Maggi M, Catalano D, Sperandeo M, Trovato G. Comprehensive clinical evidence for pulmonary embolism diagnosis and workup. Chest. 2014; 145:1173-1174.

46. Wüstner A, Gehmacher O, Hämmerle S, Schenkenbach C, Häfele H, Mathis G. Ultrasound diagnosis in blunt thoracic trauma. Ultraschall Med. 2005;26:285-290.

47. Rahimi-Movaghar V, Yousefifard M, Ghelichkhani P, et al. Application of ultrasonography and radiography in detection of hemothorax; a systematic review and meta-analysis. Emerg (Tehran). 2016;4:116-126.

48. Tomà P, Rizzo F, Stagnaro N, Magnano G, Granata C. Multislice CT in congenital bronchopulmonary malformations in children. Radiol Med. 2011;116:133-151.

49. Takayanagi N, Kagiyama N, Ishiguro T, Tokunaga D, Sugita Y. Etiology and outcome of community-acquired lung abscess. Respiration. 2010; 80:98-105.

50. Sperandeo M, Trovato FM, Dimitri L, et al. Lung transthoracic ultrasound elastography imaging and guided biopsies of subpleural cancer: a preliminary report. Acta Radiol. 2015;56:798-805.

51. Trovato GM, Sperandeo M, Catalano D. Computed tomography screening for lung cancer. Ann Intern Med. 2013;159:155.

52. Cannavale A, Santoni M, Passariello R, Arbarello P. Risk management in radiology. Radiol Manage. 2013;35:14-19.

53. Finnerty NM, Rodriguez RM, Carpenter CR, et al. Clinical decision rules for diagnostic imaging in the emergency department: a research agenda. Acad Emerg Med. 2015;22:1406-1416.

54. Kanzaria HK, McCabe AM, Meisel ZM, et al. Advancing patientcentered outcomes in emergency diagnostic imaging: a research agenda. Acad Emerg Med. 2015;22:1435-1446.

55. Singh H, Sittig DF. Measuring and improving patient safety through health information technology: the health it safety framework. $B M J$ Qual Saf. 2016;25:226-232.

56. Crawford I, Tiruta C, Kirkpatrick AW, Mitchelson M, Ferguson J. Big brother could actually help quite easily: telementored "just-in-time" telesonography of the FAST over a smartphone. Ann Emerg Med. 2011;58:312-314
57. Gulacti U, Lok U, Hatipoglu S, Polat H. An analysis of whatsapp usage for communication between consulting and emergency physicians. J Med Syst. 2016;40:130.

58. Adhikari S, Blaivas M, Lyon M, Shiver S. Transfer of real-time ultrasound video of FAST examinations from a simulated disaster scene via a mobile phone. Prehosp Disaster Med. 2014;29:290-293.

59. Katz JF, Yucel EK. Point-of-care ultrasonography. N Engl J Med. 2011; 364:2075-2076.

60. Katz JF, Yucel EK. Transthoracic ultrasound in the assessment of pleural and pulmonary diseases: use and limitations. Radiol Med. 2015; 120:404-405.

61. Katz JF, Bezreh JS, Yucel EK. Lung ultrasound in the intensive care unit: an idea that may be too good to be true. Intensive Care Med.2015; 41:379-380

62. Trovato FM, Musumeci G. Thoracic ultrasound limitations in the differential diagnosis of respiratory failure causes. Chest. 2015;148:e186.

63. Kim C, Kang BS, Choi HJ, Lim TH, Oh J, Chee Y. Clinical application of real-time tele-ultrasonography in diagnosing pediatric acute appendicitis in the ED. Am J Emerg Med. 2015;33:1354-1359.

64. Trovato GM, Sperandeo M. Sounds, ultrasounds, and artifacts: which clinical role for lung imaging? Am J Respir Crit Care Med. 2013;187: 780-781.

65. Trovato GM, Rollo VC, Martines GF, Catalano D, Trovato FM, Sperandeo M. Thoracic ultrasound in the differential diagnosis of severe dyspnea: a reappraisal. Int J Cardiol. 2013;167:1081-1083.

66. Trovato GM, Catalano D, Martines GF, Sperandeo M. Is it time to measure lung water by ultrasound? Intensive Care Med. 2013;39:1662.

67. Trovato GM, Sperandeo M. Objectively measuring the ghost in the machine: B-Lines as uncertain measures on which to base clinical assessment. JACC Cardiovasc Imaging. 2015;8:1470.

68. Trovato GM, Sperandeo M. The resistible rise of B-line lung ultrasound artefacts. Respiration. 2015;89:175-176.

69. Sperandeo M, Trovato GM, Catalano D. Quantifying B-lines on lung sonography: insufficient evidence as an objective, constructive, and educational tool. J Ultrasound Med. 2014;33:362-365.

70. Al Deeb M, Al Deeb M, Barbic S, Featherstone R, Dankoff J, Barbic D. Point-of-care ultrasonography for the diagnosis of acute cardiogenic pulmonary oedema in patients presenting with acute dyspnea: a systematic review and meta-analysis. Acad Emerg Med. 2014;21: 843-852.

71. Trovato GM, Sperandeo M, Catalano D. Ultrasound diagnosis of acute pulmonary edema: the oblivion of a great future behind us. Acad Emerg Med. 2015;22:244-245.

72. Rea G, Trovato GM. A farewell to B-Lines: ageing and disappearance of ultrasound artifacts as a diagnostic tool. Respiration. 2015;90:522.

73. Trovato GM, Catalano D, Sperandeo M. Assessment of lung ultrasound artifacts (B-lines): incremental contribution to echocardiography in heart failure? JACC Cardiovasc Imaging. 2014;7:635.

74. Catalano D, Trovato GM, Sperandeo M. Acute heart failure diagnosis by ultrasound: new achievements and persisting limitations. Am J Emerg Med. 2014;32:384-385.

75. Trovato GM, Sperandeo M. Pulmonary ultrasonography: staying within the lines prevents us finding something better on the other side. Chest. 2015;147:e236-e237.

76. Trovato GM, Catalano D, Sperandeo M. M-mode: a valuable tool in cardiology, is not yet ready to use in pneumology. Respiration. 2014; 88:518.

77. Trovato GM, Catalano D, Sperandeo M. Echocardiographic and lung ultrasound characteristics in ambulatory patients with dyspnea or prior heart failure. Echocardiography. 2014;31:406-407.

78. Trovato GM, Catalano D, Sperandeo M, Graziano P. Artifacts, noise and interference: much ado about ultrasound. Respiration. 2015;90:85.

79. Tomà $\mathrm{P}$, Owens CM. Chest ultrasound in children: critical appraisal. Pediatr Radiol. 2013;43:1427-1434.

80. Catalano D, Trovato G, Sperandeo M, Sacco MC. Lung ultrasound in pediatric pneumonia. The persistent need of chest X-rays. Pediatr Pulmonol. 2014;49:617-618. 
81. Sperandeo M, De Cata A, Molinaro F, et al. Ultrasound signs of pulmonary fibrosis in systemic sclerosis as timely indicators for chest computed tomography. Scand J Rheumatol. 2015;44:389-398.

82. Sperandeo M, Dimitri L, Pirri C, Trovato FM, Catalano D, Trovato GM. Advantages of thoracic ultrasound-guided fine-needle aspiration biopsy in lung cancer and mesothelioma. Chest. 2014;146: e178-e179.

83. Sperandeo M, Filabozzi P, Varriale A, et al. Role of thoracic ultrasound in the assessment of pleural and pulmonary diseases. J Ultrasound. 2008; 11:39-46.

84. Blozik E, Signorell A, Reich O. How does hospitalization affect continuity of drug therapy: an exploratory study. Ther Clin Risk Manag. 2016;12:1277-1283.
85. Trovato FM, Catalano D. Diagnosis of pneumonia by lung ultrasound in children and limited resources subsets. A valuable medical breakthrough. Chest. 2016;150:258-260.

86. Cantoni S, De Stefano F, Mari A, Savaia F, Rosso R, Derchi L. Audit of litigation against the accident and emergency radiology department. Radiol Med. 2009;114:996-1008.

87. Romano L, Scaglione M, Rotondo A. Emergency radiology today between philosophy of science and the reality of "emergency care". Radiol Med. 2006;111:245-251. 


\section{Supplementary material}

Video S1 Pictorial essay displaying the main features of the conditions detected by thoracic ultrasound in emergency medicine.

\section{Publish your work in this journal}

Therapeutics and Clinical Risk Management is an international, peerreviewed journal of clinical therapeutics and risk management, focusing on concise rapid reporting of clinical studies in all therapeutic areas, outcomes, safety, and programs for the effective, safe, and sustained use of medicines. This journal is indexed on PubMed Central, CAS,

EMBase, Scopus and the Elsevier Bibliographic databases. The manuscript management system is completely online and includes a very quick and fair peer-review system, which is all easy to use. Visit http://www.dovepress.com/testimonials.php to read real quotes from published authors.

Submit your manuscript here: http://www.dovepress.com/therapeutics-and-clinical-risk-management-journal 